\title{
Analysis of Corporate Investment Behaviour in Digital Technologies for Organisational Development Purposes
}

\author{
http://doi.org/10.21272/fmir.5(3).79-86.2021
}

Olena Skrynnyk, ORCID: https://orcid.org/0000-0001-8300-6616

Technology manager, Modis, Stuttgart, 70174, Germany

\begin{abstract}
In the context of this study, a literature review and the survey of German business executives were conducted. On the way to digitalisation, companies try to support or replace as many processes as possible using software and tools. The main purpose of this study consisted in investigating corporate investment behaviour in digital technologies for organisational development. Since the progress in this area in recent period is very large, consists the need to determine how do companies choose the appropriate functions and how much are they willing to invest for their execution. The study relies on a review of recent publications, statistical analysis and empirical analysis based on the results of online surveys. Behavioural determinants defined include regularity and predictability of organisational development, spending points, purpose of investment, previous experience with investment object, possible reasons against investment. It was compared which characteristics of companies (number of employees, annual turnover, age of the company, orientation) can influence a statement about the level of investment in organisational development, as well as desired functions and possible decision against investment in digital technologies. Furthermore, the current expenditures for organisational development were compared with the investments of companies with the same characteristics. The results demonstrate the different distribution of statistically collected data for personal purposes and the estimated investment volumes for digital tools for organisational development, despite relatively similar figures for current expenditure on organisational development.
\end{abstract}

Keywords: investment behaviour, organisational development, digital technologies.

JEL Classification: G3, G31, G40.

Cite as: Skrynnyk, O. (2021). Analysis of Corporate Investment Behaviour in Digital Technologies for Organisational Development Purposes. Financial Markets, Institutions and Risks, 5(3), 7986. http://doi.org/10.21272/fmir.5(3).79-86.2021

Received: 11, August, $2021 \quad$ Accepted: 8, September, 2021

Published: 13, September, 2021

Copyright: (C) 2021 by the author. Licensee Sumy State University, Ukraine. This article is an open access article distributed under the terms and conditions of the Creative Commons Attribution (CC BY) license (https://creativecommons.org/licenses/by/4.0/)

\section{Introduction}

The core of interest of this publication comprises the investment behaviour of a company, in particular in those areas and processes that provide no direct influence on performance. That digital technologies are transforming the world, attitudes and readiness for change have become self-evident. This also affects the investment behaviour of companies: on the one hand as an influencing factor, on the other hand as an investment object (Solanki et al., 2019). The study by Riera and Iijima also proves the positive impact of investments in digital technologies on selected business objectives (knowledge, growth). Nevertheless, it also points to the negative correlation concerning financial goals (Riera and Iijima, 2015). Therefore, the desire to innovate drives medium-sized companies in particular to invest in the technologies (Hernández et al., 2017). Authors illustrate, through a comprehensive international analysis, the impact of corporate investment on the successful exploitation of organisational capabilities in each of the dimensions of management, marketing and technology-specific capabilities, the improvement of organisational control, in particular as corporate alignment and formalisation, a key and moderating role in relation to all organisational capabilities and depend on the impact of corporate investment on organisational capabilities and performance (Yan et al., 2009).

The impact of directed investment corporate behaviour is significant. Alabass, based on empirical analysis 
of micro data from 500 listed companies, proves that herding behaviour of managers concerning investments positively and significantly affects firm performance. The findings show robustness in the presence of exogenous shocks to firm performance (Alabass, 2019).

\section{Literature Review}

In order to perform the literature review comprehensively, the search in the databases WOS and Scopus was performed for the terms "invest*" ON " expendit" AND " organi*ation* development". The search resulted in 1447 hits in different subject areas. These were limited to Business Management and Accounting, Social Science, Computer Science, Economic, Econometric and Finance, Mathematics and Multidisciplinary. Consequently, the number of publications found was reduced to 893. Further refinement to the last 10 years reduced the amount of hits to 505. Additional limitation of the documents to articles, conference papers, book and book chapters yielded reduction by 213 units and thus 292 publications.

Saleem et al. conduct a detailed literature review and subsequently a validation study of the developed method for measuring business value from the investment perspective and effects of ICT/IS projects from the management perspective. They prove the impact of ICT projects on social and economic development, meanwhile on the categories of strategic development, management, information, operational, transactional, organisational, infrastructure and transformational development (Saleem et al., 2020).

Hayashida et al. presents the results of their study on the dynamic analysis model for technology management activities using management of technology (MOT) (Hayashida et al., 2013).

Saetang et al. examine the role of IT deployment in business as a building block of organisational development and competitiveness and the possibility of bricolage (use and adaptation of existing IT systems and applications). They measure the acceptance of bricolage for business strategy among managers with Technology Acceptance Model (TAM) (Saetang et al., 2013).

Analysis of existing sources indicates a research gap in the area of investing or funding digital tools for organisational development. This can be explained partly by the low awareness of such IT products among companies, and partly by the low number of products on the market.

\section{Statistical analysis}

In order to gain an overview of the personnel expenses of companies, a statistical analysis was conducted based on the data collected by Genesis between 2012 and 2019. The comparison of analysis results with survey results regarding expenditure on personnel and investments for organisational development and corresponding digital technologies is intended to prove or deny hypothetically posed questions about the approximately equal relation.

According to destatis.de, $56 \%$ of Germans were employed in micro, small and medium-sized enterprises in 2019, corresponding to 2 million, 400,000 and 65,000 rounded off. This figure amounted to 15,000 for large enterprises. These numbers vary from year to year, although the ratio remains relatively the same. (destatis.de).

The information regarding the costs and investments for organisational development, as well as digital tools for this purpose, remains scarce and predominantly originates from providers. The perspective from software and service providers only considers those companies that are willing and aware of the option for external procurement of organisational development support. Thus, such data reflects the behaviour of a limited number of companies (Nobl Academy).

\section{Methodology and research methods}

For the purpose of a scientific analysis, an anonymous survey on company investments in digital technologies for organisational development was conducted with the aim of identifying the dependence of expenditure on organisational development and the willingness to invest in digital technologies on various characteristics. The survey consisted of three blocks: About the company, expenditure on organisational development and willingness to invest in digital technologies.

The block information on the company contains the questions relating to company size (number of employees, annual revenue), company age and orientation (Siller and Grausam, 2016). Concerning the number of employees, smallest, small, medium-sized and large enterprises were defined. Although the annual turnover is 
economically based on company size, the values are introduced separately in order to better crystallise the correlation between annual turnover and investments. The selection of data for company age was specified to determine whether and how long the company and organisational development has as a company strategic characteristic. Furthermore, respondents were asked whether their company is owner-managed or familymanaged. The answers to these questions determine whether the statement about better organisational development in such companies is true. The question on resource intensity in a company points to the number of the largest sources of expenditure and offers for selection personnel (labour-intensive), operating resources, materials, and energy.

The second block explores expenditure on organisational development and provides answers to questions about the predictability and regularity of expenditure, the content of expenditure units, the amount of expenditure per employee and the average tasks for each time (expenditure on organisational development divided by the number of employees). The consideration of expenditure in terms of number of employees reflects the difference in cost allocation.

The third block focuses on the willingness to invest in digital technologies, including artificial intelligence, for organisational development. The business leaders were asked about their willingness to apply digital tools for organisational development, for which purposes they would be willing to invest in digital technologies for organisational development. Here, the functions of collection, analysis of data, recognition of patterns in organisational events and prediction of development in organisational events as well as simulation were posed for selection. Furthermore, the question arises about the amount of the contribution to be invested per employee. Then depends the question about the possible reasons that hinder the management from investing in digital technologies for organisational development. The options include lack of trust, high cost, lack of knowledge and competence, lack of personnel for implementation and monitoring, and lack of time. The results obtained should answer the following research questions and reveal the correlations.

\section{Research questions:}

$>$ How much do companies invest in organisational development? External resources (knowledge/technology/tools) and internal resources (man-hours for meetings/training/... on both sides)

$>$ How does the level of investment in organisational development depend on firm size, firm value, firm age?

$>$ Are firms willing to invest in AI for organisational development?

$>$ If not, why (lack of trust, high costs, lack of knowledge and competences, lack of time)?

The survey aims to answer these questions and explore other facets of corporate decisions to invest in digital tools for organisational development through optional contributions.

\section{Results}

Statistical analysis of expenditures on personnel at different company sizes revealed the correlations illustrated in Table 1.

Table 1. Correlation between company size and expenditures on personnel (own processing)

\begin{tabular}{|c|c|c|c|c|}
\hline Year & Micro & Small & Medium & Large \\
\hline $\mathbf{2 0 1 2}$ & 3.5 & 4.1 & 4.0 & 1.2 \\
\hline $\mathbf{2 0 1 3}$ & 3.6 & 4.1 & 4.2 & 4.1 \\
\hline $\mathbf{2 0 1 4}$ & 3.2 & 3.9 & 3.9 & 1.2 \\
\hline $\mathbf{2 0 1 5}$ & 3.4 & 3.9 & 3.9 & 1.3 \\
\hline $\mathbf{2 0 1 6}$ & 3.3 & 3.7 & 3.9 & 1.2 \\
\hline $\mathbf{2 0 1 7}$ & 3.3 & 3.7 & 4.4 & 1.2 \\
\hline $\mathbf{2 0 1 8}$ & 3.1 & 3.6 & 4.4 & 1.2 \\
\hline $\mathbf{2 0 1 9}$ & 3.2 & 3.8 & $\mathbf{4 . 1}$ & 1.1 \\
\hline Average & $\mathbf{3 . 3}$ & $\mathbf{3 . 8}$ & $\mathbf{1 . 2}$ \\
\hline
\end{tabular}

Sources: Own representation based on statistical data from destatis.de (2021).

Table 1 compares the proportion of personnel expenses per person employed proportional to the average turnover of companies of one size. As expected, the numbers are low for large enterprises and higher for medium-sized and small enterprises. The difference to the large companies is obvious and can be explained in different ways (e.g. the orientation of large companies or the positive economies of scale).

64 companies completely participated in the survey, of which 39 were micro, 10 small, 13 medium and 2 large. Despite the classical division of company sizes according to number of employees and turnover, some 
participating companies demonstrate the deviations, which can be attributed to the orientation (intensity).
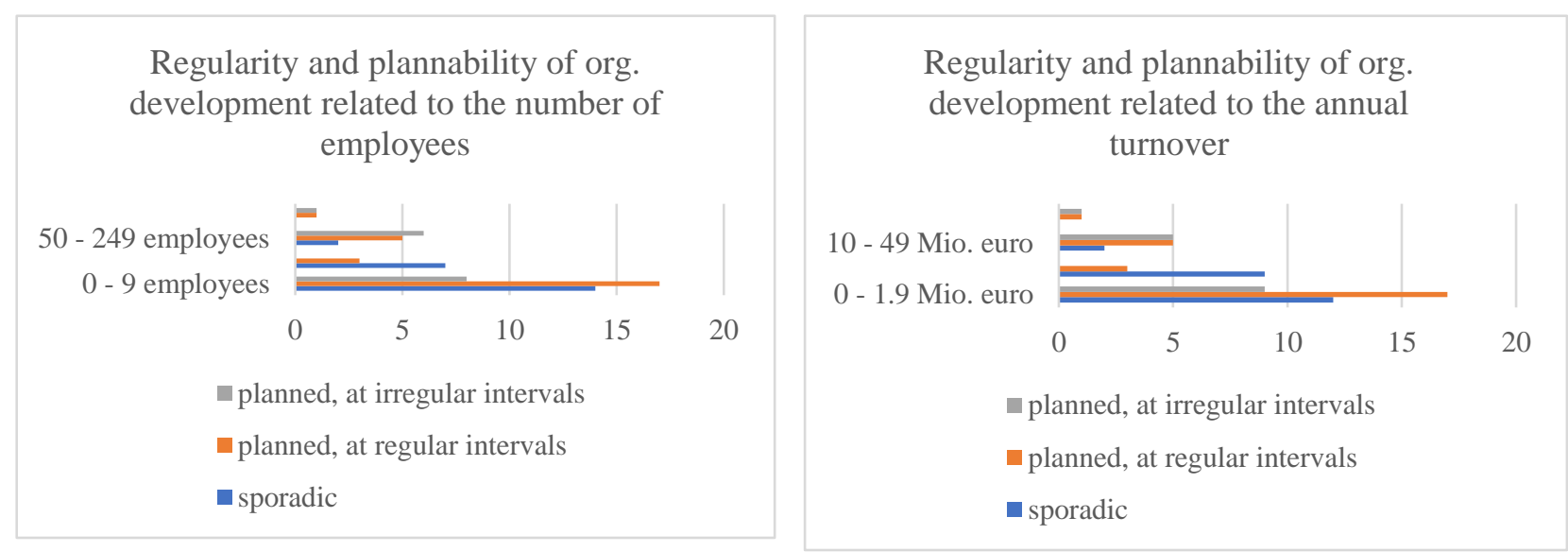

Figure 1. Regularity and plannability of organisational development related to the company size

Sources: Own representation

The survey reveals that the largest number of companies that sporadically conduct organisational development activities employ up to nine people and have an annual turnover of up to 9 million euro. Companies that plan and regularly implement organisational development activities have the number of employees from 50 and turnover of 10 million euro. The survey indicates that the majority of business leaders surveyed plan organisational development but perform it irregularly (Figure 1).
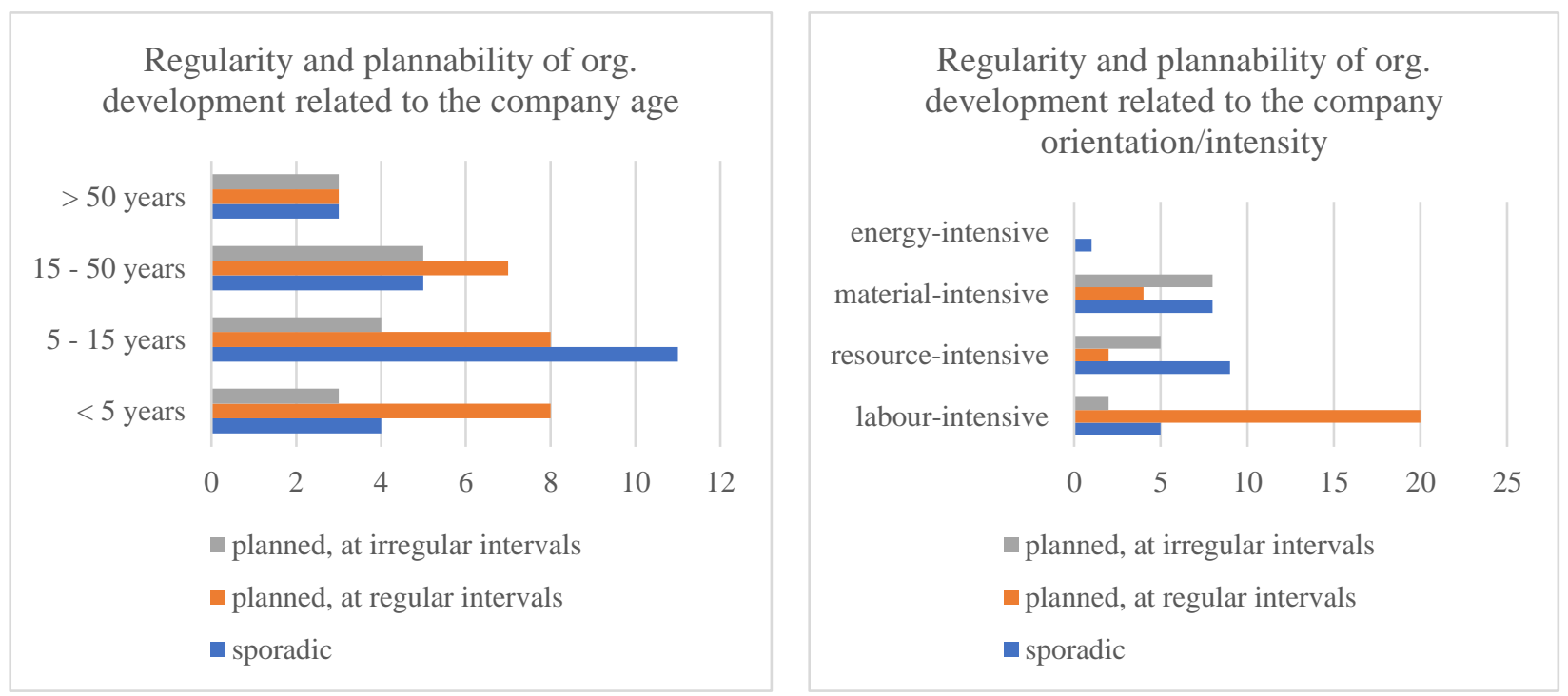

Figure 2. Regularity and plannability of organisational development related to the age and orientation of the company

Sources: Own representation.

Remarkable results demonstrate companies existing for 5-15 years: the number of sporadically acting companies is the highest and amounts to about eleven. Enterprises with the age younger than 50 years show relatively similar dispersion in planned activities with regular and sporadic interval regardless of the number of enterprises (Figure 2).

The companies that are most dependent on human labour plan and implement their organisational development activities on a regular basis. In contrast, the number of companies that act sporadically is predominantly distributed between resource-intensive and material-intensive. Energy-intensive companies indicate sporadic behaviour in organisational development, which is caused by the small number of participants (Figure 3).

Analysis of expenditure units for organisational development averaged across all companies reflects that the most prioritised items are external knowledge and internal knowledge (34\% and $31 \%$ of respondents respectively), followed by implementation of organisational development activities (27\%) and external 
technologies and tools (5\%), finally internal technologies and tools (3\%).

Respondents indicate that their companies have low shares of digital tools for organisational development, on average $15 \%$.

All respondents have shown willingness to invest in software for analysis of data. This is followed by digital support, collection of data and then, in equal proportions, recognition of patterns, prediction of development and simulation of organisational events.

As possible reasons for deciding against investing in digital technologies for organisational development, management chose high costs, lack of knowledge and skills and lack of time in equal parts. Lack of staff for implementation and tracking was prioritised lower. The option lack of trust is not recognised as a reason against investment.

The comparison of current spending on organisational development and investment in digital technologies for organisational development per employee shows the following correlations:

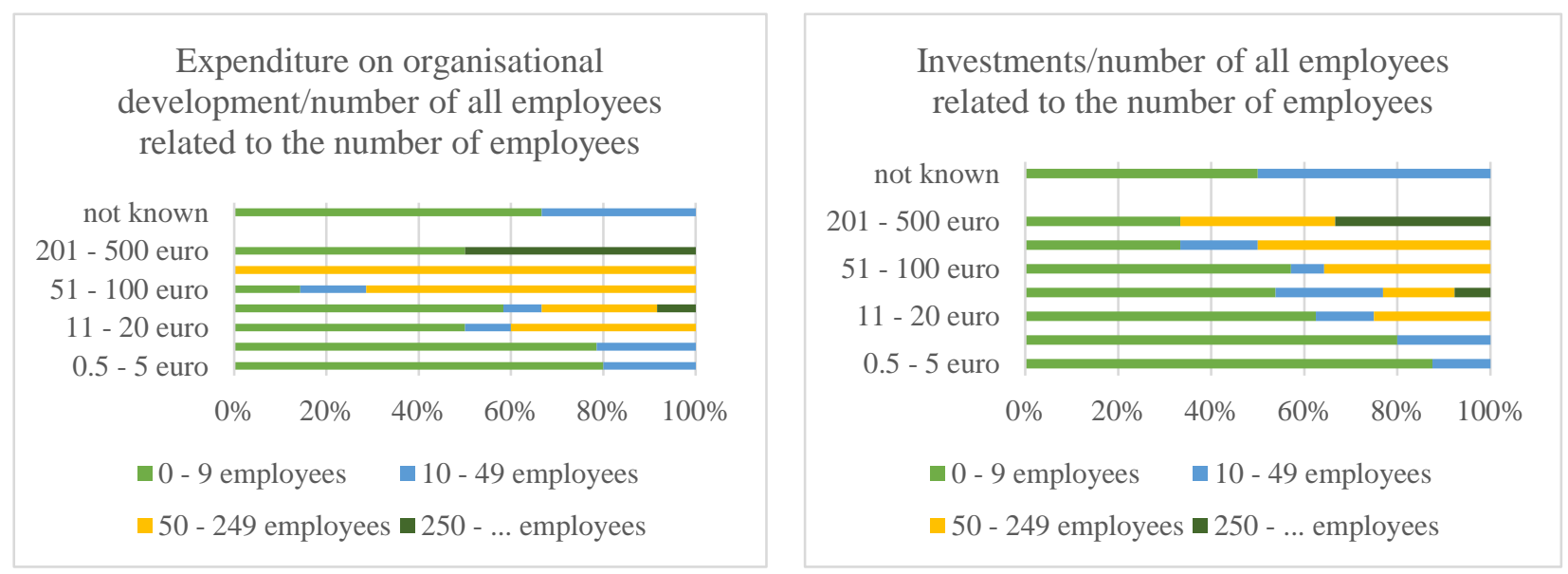

Figure 3. Comparison of the current expenditure on organisational development and investment in the digital technologies for organisational development per one employee related to the number of employees

Sources: Own representation.
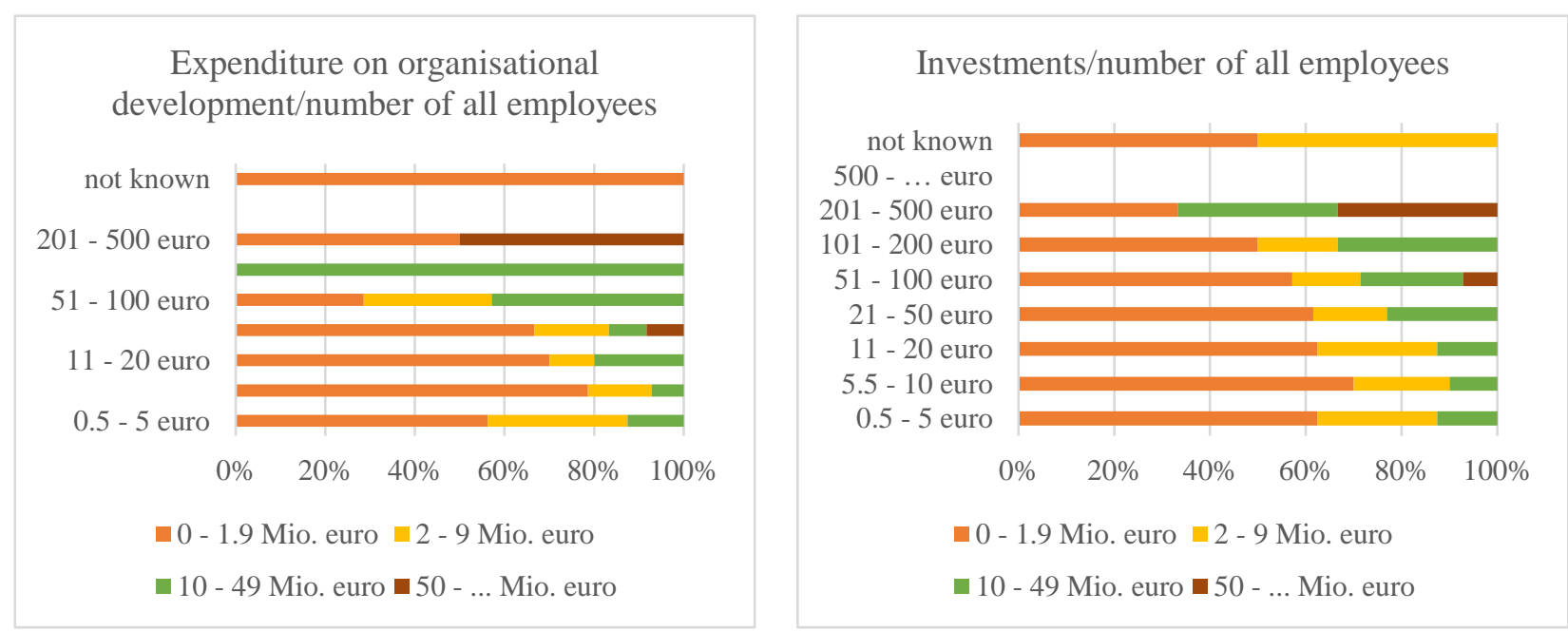

Figure 4. Comparison of the current expenditure on organisational development and investment in the digital technologies for organisational development per one employee related to the annual turnover

Sources: Own representation

Companies with small numbers of employees spend less per employee on organisational development than those with larger numbers of employees. However, they are willing to spend more per employee on investments (Figure 3 ). The trend is similar for companies with a certain annual turnover: the companies with a low annual turnover would like to invest more in digital tools for organisational development (Figure 4). The average figures for investments shown in Table 2 differ from the expenditure on personnel (Table 1). The difference results from the small number of respondents, especially the large companies. 
Table 2. Correlation between company size and investment in digital technologies for organisational development per employee (own processing)

\begin{tabular}{|c|c|c|c|c|}
\hline Investment & Micro & Small & Medium & Large \\
\hline$(\ldots)$ & 31.6 euro & 28.6 euro & 70.5 euro & 164 euro \\
\hline
\end{tabular}

Sources: Own representation.

For companies with a high number of employees and large annual turnover, the distribution reveals a very similar pattern, showing greater spending per employee and distributed expectations for investment costs. The diffuse distribution of companies at different ages shows that they are willing to invest in organisational development regardless of current expenditure, the most active idea similar to expenditure is among companies aged 5-15 years (Figure 5).
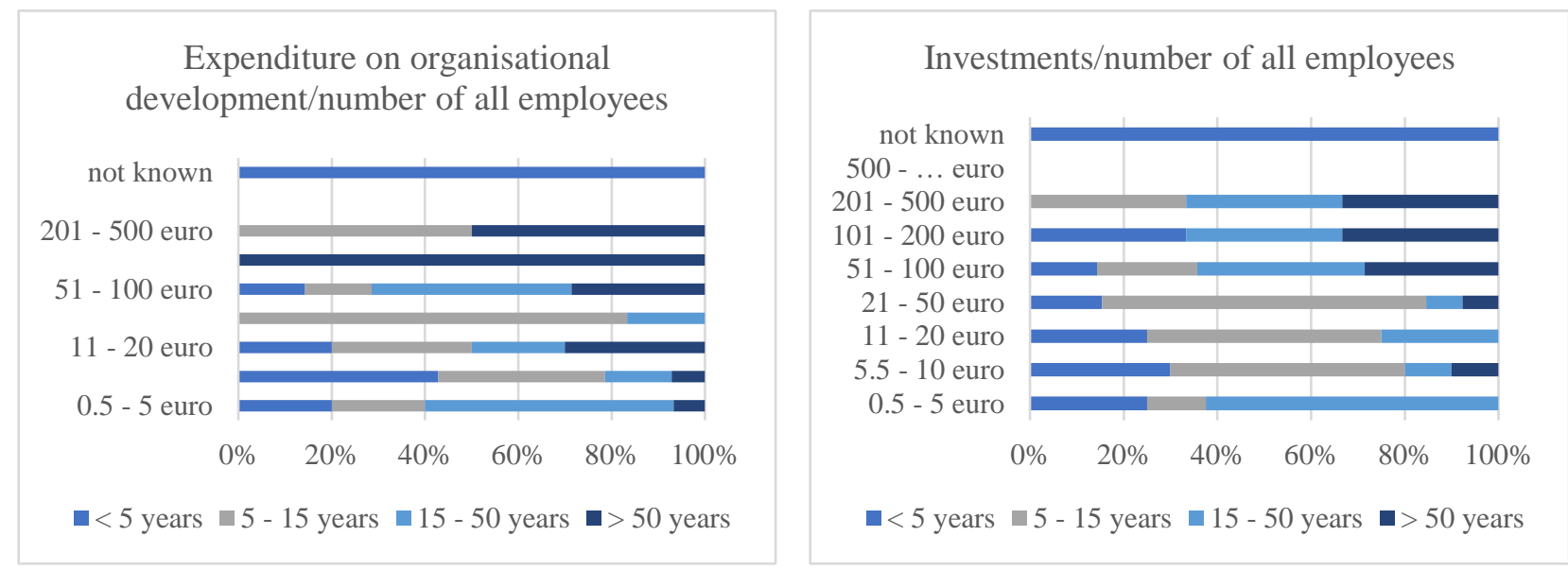

Figure 5. Comparison of the current expenditure on organisational development and investment in the digital technologies for organisational development per one employee related to the age of the company

Sources: Own representation

Corresponding to the data of labour-intensive enterprises, whose share of respondents was the largest, and material-intensive enterprises, they spend approximately the same amount on organisational development, but have a certain idea of the possible investments: for labour-intensive from 5.5 euro, for material-intensive up to 200 euro with prioritisation of per employee sum between eleven and 20 euro. Energy-intensive enterprises have the highest expenditure, which is due to the small number of respondents. These companies are willing to invest the most, up to 500 euro (Figure 6). A remarkable correlation is reflected in the comparison of owner-led and family-led companies and management-led companies: although the tendency of family-led companies is discontinuous spending per employee on organisational development, with numbers reaching up to 50 euro and then jumping to 101-500 euro, the two types of management show a continuous investment expectation (Figure 7).
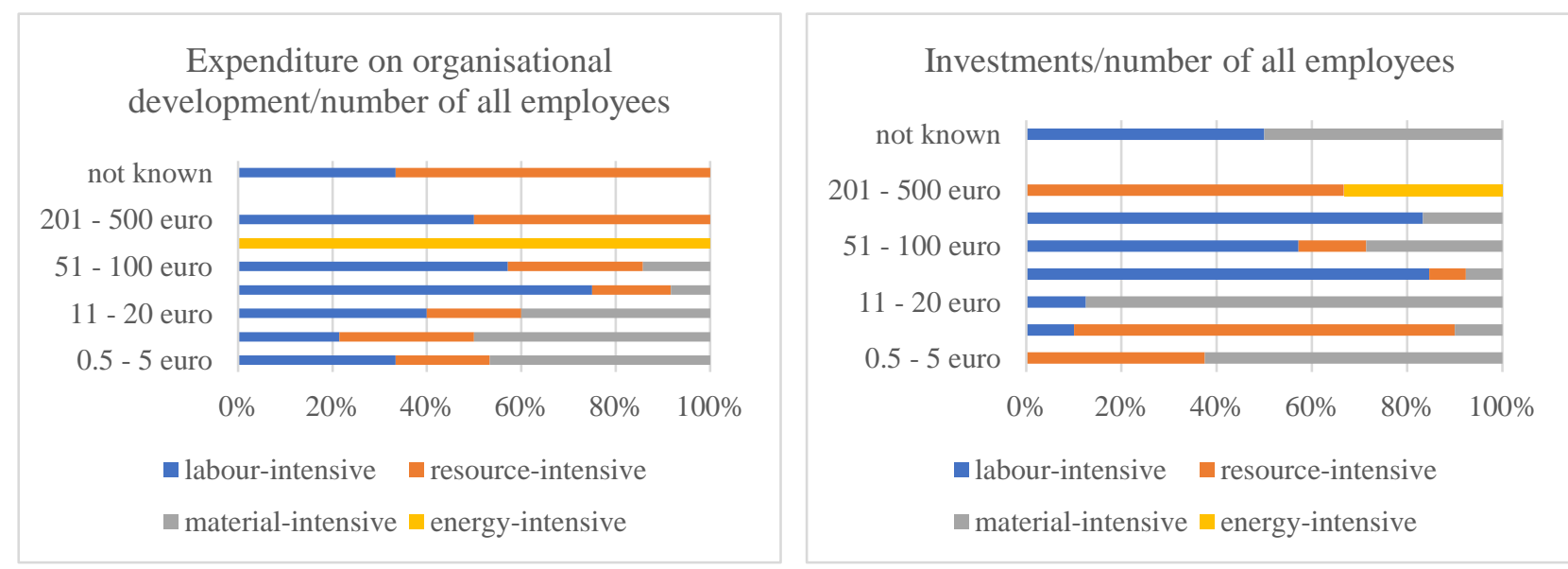

Figure 6. Comparison of the current expenditure on organisational development and investment in the digital technologies for organisational development per one employee related to the orientation of the company

Sources: Own representation. 

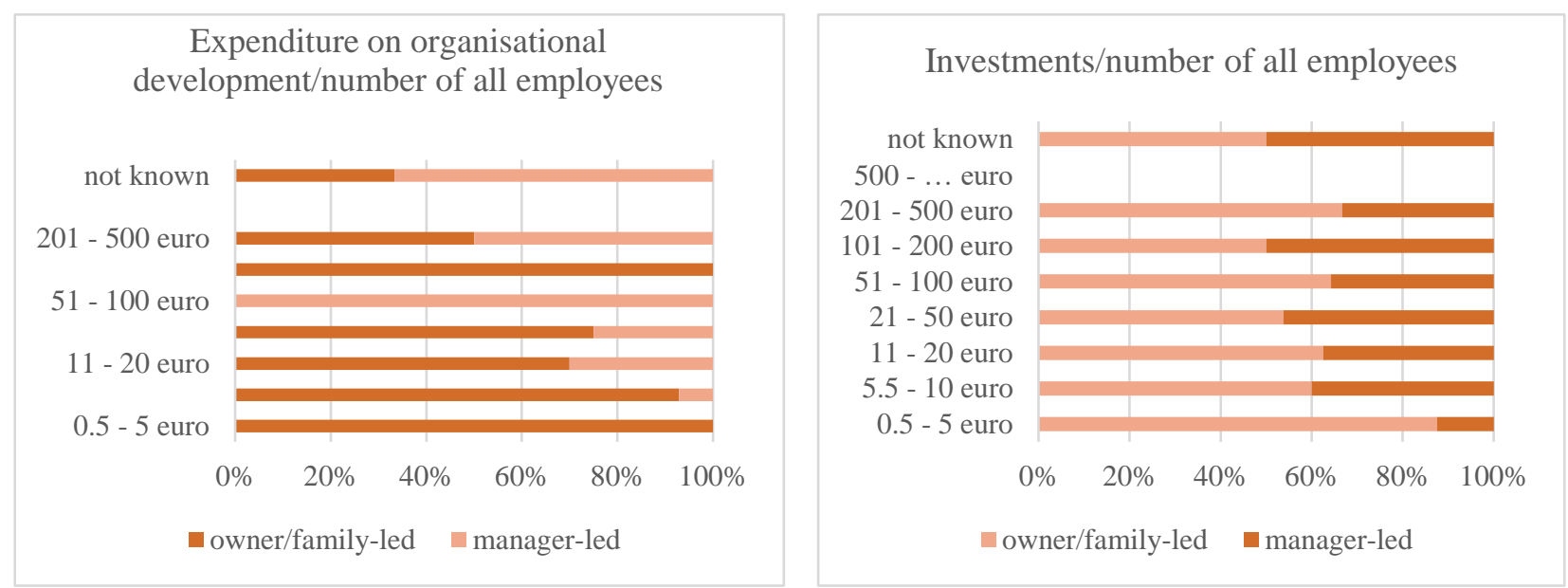

Figure 7. Comparison of the current expenditure on organisational development and investment in the digital technologies for organisational development per one employee related to the leading person

Sources: Own representation.

\section{Limitations}

Limitations of the survey relate to two aspects: Number and selection of respondents. Since this survey is conducted online, the selection of respondents cannot be influenced. Despite possible planning, the extensive coverage of surveyed companies would not be sufficient, because on the one hand, a multitude of variable parameter combinations exist and on the other hand, the distribution of companies and the obtaining of data would be too costly, which is a possible research direction. According to these numbers and the margin of error of $10 \%$, the sample size formula results in the following quantity of business leaders interviewed: for micro, small-sized enterprises 97 respondents respectively, for medium and large-sized each 96 respondents. The precise calculation is determined according to the following formula using sample size calculator (Sample size calculator):

$k=\frac{\frac{z^{2} \times p(1-p)}{e^{2}}}{1+\left(\frac{z^{2} \times p(1-p)}{e^{2} N}\right)}$

where $\mathrm{k}$ - number of required respondents

$\mathrm{N}$ - population size (number of companies)

e - error range as a decimal number (we define as $10 \%$ )

$\mathrm{z}$ - confidence level (we take $\mathrm{z}=1.65$ for confidence level $90 \%$ )

$\mathrm{p}$ - percentage as decimal number (we choose $\mathrm{p}=0.5$ for optimal sample size).

\section{Conclusions}

The study conducted on the basis of statistical data and empirical analysis reveals how investment behaviour is dependent on company characteristics.

Furthermore, the potential exists in researching and comparing country-specific prices for organisational development services, the supply of organisational development software and the willingness of companies to invest in it.

\section{References}

1. Alabass, H.S.H.H. (2019). The impact of corporate investment behaviour on the corporate performance: Evidence from an emerging market. Journal of Management Information and Decision Science, 22. [Link]

2. Statistisches Bundesamt. Retrieved on 10.09.2021. [Link]

3. Hayashida, H., Funashima, H., Katayama-Yoshida, H. (2013). Understanding management of technology as a dynamic capability: Case study by dynamic analysis model for technology management activities. 2013 Proceedings of PICMET 2013: Technology Management in the IT-Driven Services 6641600, 26-32. [Link] 
4. Hernández, H.G., Cardona, D.A., Del Rio, J.L. (2017). Strategic direction: Projection of technological innovation and administrative management in small enterprises. [Direccionamiento estratégico: Proyección de la innovación tecnológica y gestión administrativa en las pequeñas empresas]. Informacion Tecnologica, 28(5), 15-22. [Google Scholar]

5. Nobl Academy (2016). How Much Should You Pay for Org Design \& Development? [Link]

6. Riera, C. and Iijima, J. (2015). Does Investment in Digital Technologies Yield Digital Business Value? The Digital Investment Paradox and Knowledge Creation as Enabling Capability. In Proceedings of the 10th International Joint Conference on Knowledge Discovery, Knowledge Engineering and Knowledge Management (IC3K 2018), 3, 208-215. [Google Scholar]

7. Saleem, F., Salim, N., Altalhi, A. H., Ullah, Z., AL-Malaise AL-Ghamdi, A., Khan, Z. M. (2020). Assessing the effects of information and communication technologies on organizational development: business values perspectives. Information Technology for Development, 26(1), 54-88. [Link]

8. Saetang, S., Haider, A., Ku Bahador, K.M. (2013). Building effective organizational management with bricolage and it governance on technology acceptance model. Proceedings of the International Conference on Electronic Business (ICEB), 132-138. [Link]

9. Sample size calculator. Retrieved on 10.09.2021. [Link]

10. Siller H., Grausam A. (2016). Management in EPU und Kleinstunternehmen. In: Selbstcontrolling für Selbständige und kleine Unternehmen. Springer Gabler, Wiesbaden. [Link]

11. Solanki, S., Wadhwa, S., Gupta, S. (2019). Digital Technology: An Influential Factor in Investment Decision Making. International Journal of Engineering and Advanced Technology, 8, 27-31. [Link]

12. Yan, Y., Ding, D., Mak, S. (2009). The Impact of Business Investment on Capability Exploitation and Organizational Control in International Strategic Alliances. Journal of Change Management, 9(1), 49-65. [Google Scholar] 